\title{
Transforming Engineering Education Exploiting Inveterate Symbiosis Between Science and Spirituality
}

\author{
S. K. Jha \\ Division of Instrumentation and Control Engineering, \\ NSIT, Dwarka, New Delhi \\ jhask2@yahoo.co.in
}

\begin{abstract}
The main objective of the present paper is to investigate and exploit the inveterate symbiosis between science and spirituality. From the stand point of human system being most complex in the world and creator of all the system, need to be more conscientious and scrupulous in order to develop advanced form of civilization. In view of contagious and ubiquitous terrorism, barbarity and savagery, its root causes and remedy has been tried to be found out. Analogy between man and machine has been taken to understand the scope of rapprochement between bestial instinct and humane instinct. These tasks has been accomplished by taking inference of different control approaches such as transfer function approach, pole placement approach and above all robust and optimal control approaches. True implication of success and failure is analogically portrayed by the example of DC machine. Psychic control of human being vis-à-vis the stability of control systems with reference to the left half and right half s-plane poles and zeros has been analogically and symbiotically highlighted and presented.
\end{abstract}

Keywords-DC Machine, Optimal, Pole-Placement, Root Locus, Robust, Science, Spirituality, Symbiosis, Transfer Function

\section{S. K. Jha}

Division of Instrumentation and Control Engineering, NSIT, Dwarka, New Delhi email:jhask2@yahoo.co.in

\section{Introduction}

From time immemorial, ancient order of monks is exploiting science and spirituality for better, meaningful and invigorating life. In these recent years study and implementation of robust, optimal and yet spiritual human system has been a matter of concern for educationist and philanthropist worldwide and drawn the attention of many social reformers. In view of the burgeoning terrorist activities based on sectarianism, bigotry, regionalism, and communalism etc it is very imperative to look into the reason behind all these heinous activity despite scientific and technological development. After meticulous study, the main reason has been found to be the missing link between science, technology and spirituality. Science, no doubt has made a quantum jump but ethics and rectitude is missing, which if not resuscitated and assimilated with the science very soon, may create havoc throughout the world. Dropping of atom bomb on Hiroshima and Nagasaki glaringly buttresses this point [1-3].

One great saint of Indian origin, Swami Vivekananda, delivered his famous speech in 1893 in the parliament of religion held at Chicago, America, in which he had stated- "Sectarianism, bigotry and its horrible descendent, fanaticism has long possessed this beautiful earth and if it were not for these demonic forces human civilization would have been far more advanced than it is now". After he returned from America he exhorted to Indians- "if you want to take something from the western countries that is modern science and technology but in return you should have 
something to be given to them in return and that is our spiritual background and rich cultural heritage". The apparent connotation and implication behind this exhortation is very conspicuous and irrevocable in the sense that for the nurturing of human civilization, science intertwined with spirituality is must [1-3].

In modern control approach, the designed system is said to be robust if it remains insensitive and unperturbed to external disturbance, perturbation and uncertainties. Analogically a controlled mind of human as a system is said to be robust if it remains insensitive and unperturbed to external disturbance, perturbation and uncertainties [4-16]. Ironically and verily, it can be unequivocally said that our mind is no longer robust to face the unpredictable external disturbance and vicissitudes, despite being affluent and knowledgeable. Wealth and scientific knowledge only cannot provide the peace and happiness in lives but if the means by which wealth is earned is utilitarian knowledge then peace and happiness is guaranteed. Ultimate aim of human being is to get peace and happiness and for this, in my view, science has to marry with spirituality and then the coming generation will surely be leading a peaceful and contented life.

In order to correlate science and spirituality, it is pertinent here to invoke the difference between classical and modern control approaches. While designing classical control, we were least bothered as to whether the system designed is robust and optimal or not. Classical control system design is generally a trial and error process in which various methods of analysis are used iteratively to determine the design parameters of an "acceptable system". Acceptable performance is generally defined in terms of time and frequency domain criteria such as rise time, settling time, peak overshoot, and gain and phase margin. Classical design techniques have been successfully applied to Linear Time Invariant (LTI), Single Input Single Output (SISO) systems with zero initial conditions; however, radically different performance criteria must be satisfied by the complex, Multiple Input Multiple Output (MIMO) systems required to meet the demands of modern design requirement. For example the design of spacecraft attitude control system that requires minimizing fuel expenditure is not amenable to solution by classical methods. A new and direct approach to the synthesis of these complex systems, called optimal control theory, has been made feasible by the development of the digital computer [17-28].
In this paper, inveterate symbiosis between science and spirituality has been endeavored to be exploited by taking a few engineering system and analogically correlating it with subtlest human system. Stability analysis of complex human system during perturbed condition is corroborated with the accompaniment of a few scientific topic such as DC machine, Transfer function, root-locus, pole-placement etc. The paper is organized as follows: Section I gives the introduction of the proposed necessity of exploiting the link between science and spirituality. Section II discusses the inherent analogy between DC machine and human being. Analogy between transfer function approach and human as a system is described in section III. Section IV deals with the analogy between pole placement approach and equanimity of mind. Summary and discussions are covered in Section V. Section VI terminates with conclusion.

\section{Analogy Between DC Machine and Human Being}

DC machine are of two types: DC Generator and DC Motor. In DC machine stator houses the DC field winding and rotor houses the armature winding. The basic principle of DC generator is that when rotor is rotated by prime mover, keeping the DC field magnet housed in stator stationary, then with the help of commutator, DC current is generated in the armature winding placed on rotor. In a reverse way the basic principal of DC Motor is that when DC current is supplied to armature winding along with that to field magnet then a unidirectional torque is produced following the lenz's law which rotates the rotor. It is worth noting here that in DC generator, motoring action takes place and in DC motor, generating action takes place.

First of all we take into cognizance the motoring action of DC generator and then the generating action of DC motor. In DC generator when current is generated in armature winding, then simultaneously motoring action also starts, meaning thereby that a reverse torque is produced against the torque which is applied for generating purposes. If it were not for the presence of back torque no energy conversion from mechanical to electrical would have taken place. So back torque is must for generation of electricity by DC generator. When we take its analogy with human success, it is worth noting that human success is not possible without adversity and hardships which is akin to the fact that generation of DC current is not possible without back torque in DC generator. There is 
famous quotation also, buttressing this factual analogy: "Adversity is better than prosperity".

Similarly in DC motor, when torque is produced and rotor begins to rotate, generating action simultaneously takes place, meaning thereby that a back EMF i.e. reverse voltage is produced against the voltage which is applied for motoring purposes. If it were not for the presence of back EMF no energy conversion from electrical to mechanical would have taken place. So, back EMF again is must for generation of torque by DC motor. Again for DC motor, we see the same analogy in context with human being is that success without predicaments and impediments cannot be materialised. Life is not a bed of roses rather it is fraught with vicissitudes, ordeals, trials and tribulations and without which real success is not possible. By this example of electrical machine, we human being should take a firm lesson to fight the formidable challenges and ordeals by indomitable courage and then only may kiss the ecstatic pleasure of real success. Person need to be robust to cope up with the challenges of life and thereby give the optimal performance.

\section{Analogy Between Transfer Function Approach and Human as A System}

Transfer function is defined as the ratio of Laplace transform of output and Laplace transform of input assuming the system to be initially relaxed. As we know that the main component of any system is energy storing element or energy dissipating element. For example if we take the electrical system then energy storing elements are inductor and capacitor and the energy dissipating element is resistor. Similarly if we take mechanical system such as spring mass damper system, then energy storing elements are mass and spring constant while the energy dissipating element is damping coefficients. As we know that the first and foremost step in designing a control system is to develop the mathematical modelling of the system. Transfer function approach is nothing but simplified method to find the mathematical modelling of single input single output (SISO) system. If the system is not initially relaxed i.e. if the initial condition is not zero, the analysis of mathematical modelling becomes complex. There is always possibility that energy storing elements may have had some initial energy stored in it, but in order to obviate complexity, system is assumed to be initially relaxed. If we make analogy with human as a system we find that the main reason behind animosity between one person and other person is that they are not able to forget the past. There is a proverb in English "Let the dead past bury its dead, act-act in the living present". This is not confined to a few individuals only but extends to different countries of the world which are engaged in internecine battle. For example, the internecine cold war between India and Pakistan, between Israel and Philistine etc, are grave reminder of the fact that they are not oblivious of their past hostility. So it is beneficial to bury in oblivion the past animosity and disputes and turn over a new leaf otherwise the spiralling jingoism may devour the entire humanity.

So taking cue from transfer function approach where past is buried in oblivion for developing simplest relationship, human being ought also to bury the hatchet and give shape to a new era of simplicity not complexity, friendship not animosity. Further, as the development in control design technology switched from classical transfer function approach to state-space based modern control approaches where initial conditions are no longer condoned but incorporated, human being should also switch over from classical to transcendental stage with the rider that reminiscence ought to be only of the pleasant past and not of the haunting past. The form and structure of "Astanga Yoga" is also a transformation from following simple rule to the ecstatic state of onerous Samadhi state just like what we see in control system i.e. transformation from transfer function approach to robust/optimal control approach $[11,17]$. This kind of similitude between science and spirituality, as far as sublimation from classical to subliminal/transcendental state is concerned, may give a new dimension to the otherwise hackneyed and perverted world and herald the onset of paradigm turnaround and metamorphosis in the educational system worldwide.

\section{Analogy Between Pole Placement \& Equanimity of Mind}

The pole placement method is somewhat similar to root locus method in that we place closed loop poles at desired locations. The basic difference is that in the root locus design we place only the dominant closed loop poles at the desired locations, while in the pole placement design we place all closed loop poles at desired locations. If the system considered is completely state controllable, then poles of the closed loop system may be placed at any desired locations by means of state feedback through an appropriate state feedback gain matrix. The process of determining the 
desired closed loop poles are based on either the transient response or frequency response requirements, such as speed, damping ratio, or bandwidth, as well as steady state requirements. The main goal of a feedback design is to stabilize, if it is initially unstable or to improve the relative stability. In pole placement based controllers the control law is a linear time varying function of the system states hence the measurement of all of the state variables must be available to implement the control law. A system is said to be controllable at any time if it is possible by means of an unconstrained control vector to transfer the system from any initial state to any other state in a finite interval of time. The concepts of controllability were first of all introduced by Kalman and play an important role in the design of control systems in state space. The solution to this problem may not exist if the system considered is not controllable. As we know that for pole placement approach, control vector is a function of state variables. Hence all the state variables must be measurable [11, 13, 27].

As we know that the journey of root locus starts from open loop poles and culminates at open loop zeros. In contrast, the journey of human life begins from five fundamental elements (earth, water, fire, ether and air) and culminates to the same five fundamental elements. Nobody can boast to have put on an armor of invincibility and one day everybody has to meet the hard truth, the demise i.e. zero. As we know that if the roots of characteristics equation lie on left half of s-plane, system is stable and if on right half of s-plane, then system becomes unstable [7-9]. As is obvious from the preliminaries of pole placement control, that for pole-placement design, system must be controllable i.e. transferring the system from any initial state to any other state in a finite interval of time is possible. If we think human being as a system, it has also got left half and right plane just like s-plane and in order to control the perturbed and chaotic mind, human should be controllable. As in a pole placement based controllers, the control law is a linear time varying function of the system states, same thing happens with human as a system. A person knows better than anybody else about himself or herself and hence in order to control oneself, he/she must have knowledge of entire psychology quite akin to state variable. In the same way if a teacher wants to control his disciple, he must have complete information about psychological realms of his disciple quite akin to state variables. The controllability of a system may have a great semblance of simile with the mendicant who reaches to state of Samadhi as illustrated meticulously in Indian philosophy of Astang Yoga. Just like controllable system, person reached in state of Samadhi can transfer himself/herself from any initial state to other state harnessing the supernatural divinity. By following the tenets of Astang Yoga circumspectly, person may display robust behavior, and give the optimal performance which is need of the hour.

\section{Summary and Discussion}

The main objective of this article is to transform engineering education by exploiting the inveterate symbiosis between science and spirituality. Here utmost care has been taken to demistify the otherwise mystified aspect of interrelationship between science and spirituality. As the maxim goes: "All roads lead to same destination" was not verifiied in context with science and spirituality. Here, having delved deep into metaphysical and scientific details, I have found that both are inextricably interwoven and are nothing but synergistic amalgamation i.e, fusion of spirit and body. We have reached to this view after taking numerous analogy, some of them described in previous sections. By way of invoking analogy between DC machine and human as a system, transfer function approach and pole placement versus equanimity of mind, it is apparent that if this symbiosis is tenaciously followed and preserved, human society and civilization is bound to exalt to a newer height and the world may become a paradise i.e, a place worth living. Furthur, if we want to save this mother earth from apocalypse and cataclysm, we need to clairvoyantly see the immanent fusion between science and spirituality. In this paper utmost endeavour has been made to establish the fact that science and spirituality doesn't entail to be intertwined rather they are already intertwined i.e, science has spirituality embedded in it and vice-versa.

\section{Conclusions}

In this paper the inveterate symbiosis between science and spirituality has been investigated and proposed to be exploited for catapulting and sublimating the human civilization to transcendental level. Human system being most complex in the world and creator of all the system, need to be more conscientious and scrupulous in order to develop advanced form of civilization. In view of endemic and omnipresent nature of terrorism, barbarity and savagery, its root causes and remedy has been tried to be found out. Analogy between classical and modern 
control approach has been taken to understand the scope of rapprochement between bestial instinct and humane instinct. These tasks has been accomplished by taking inference between different control approaches such as transfer function approach, pole placement approach and above all robust and optimal control approaches. True implication of success and failure is analogically portrayed by the example of DC machine. Psychic control of human being vis-à-vis the stability of control systems with reference to the left half and right half s-plane poles and zeros has been analogically highlighted and presented. Here the shrouded mystery between science and spirituality has been divulged out and the myth that spirituality has nothing to do with science is completely busted. Spirituality which is immanently imbued with science has been manifested in this paper. Conclusively, it can be emphatically said that science without spirituality will do nothing but annihilation and sacrilege of humanity. Therefore science in conjunction with spirituality and for that matter the value added education only can sublimate the human civilization to a new height of transcendental level.

\section{References}

[1] Times of India, Speaking Tree, Sunday times sources.

[2] Srimadbhagwadgita sources.

[3] Autobiography of Gandhi: An experiment with my truth.

[4] S. K. Jha, A.K. Yadav, Prerna Gaur and J.R.P. Gupta, "Robust Stability Analysis of DC Servo Motor for Attitude Control of Aircraft using Arguon's Theorem," Journal of Control Engineering and Technology, vol. 4, issue 2, pp. 127-134, April 2014.

[5] N. Tan and D. P. Atherton, "Stability and performance analysis in an uncertain world," IET Comput. Control Eng. J., vol.11, no.2, pp.91-101,Apr. 2000.

[6] S. P. Bhattacharyya, Aniruddha Datta, and L. H. Keel, "Linear Control Theory: Structure, Robustness and Optimization", CRC Press, Taylor and Francis Group, New York, 2009.

[7] R. W. Brockett, "Poles, Zeros, and Feedback: State Space Interpretation," IEEE Transaction on Automatic Control, AC-10 (2), pp. 129-135, 1965.

[8] J. C. Doyle, and G. Stein, "Multivariable Feedback Design: Concepts for a Classical/Modern Synthesis," IEEE Transaction on Automatic Control, AC- 26 (1), pp. 4-16, 1981.

[9] J. S. Freudenberg and D. P. Looze, "Right Half Plane Poles and Zeros and Design Tradeoffs in Feedback Systems," IEEE Transactions on automatic Control, AC-30(6), pp. 555-565. 1985.

[10] M. Gopal, Digital Control and State Variable Methods Conventional and Intelligent Control System, Tata McGraw Hill Education Pte. Ltd., Third Reprint, 2009.

[11] D. E. Kirk, Optimal Control Theory: AN INTRODUCTION, Prentice Hall, Englewood cliffs, New Jersey, 1970.

[12] S. K. Jha, H. Parthsarathy, J. R. P. Gupta and P. Gaur, "Verification of the Veracity of Brachistochrone Curve and Evolution of Optimal Control," India International Conference on Power Electronics (IICPE), N. Delhi, India, pp. 1-4, Jan. 2011.

[13] K. Ogata, Modern Control Engineering, Prentice Hall, USA, Third Edition, 1997.

[14] K. I. T. Richardson, "The Gyroscope Applied," The Philosophical Library, New York, 1954, pp. 261-264.

[15] D. McRuer and D. Graham, "Eighty Years of Flight Control: Triumphs and Pitfalls of the System Approach," Journal of Guidance and Control, vol. 4, July-August 1981.

[16] B. C. Kuo, Farid Golnaraghi, Automatic Control System, John Wiley and Sons (Asia) Pte Ltd, Eighth Edition, 2003.

[17] L. H. Keel and S. P. Bhattacharyya, "Robust, Fragile or Optimal?," IEEE Trans. Automat. Contr., vol. AC-42, no. 8, pp. 1098-1105, 1997.

[18] Iqbal Husain, Electric and Hybrid Vehicles, Design Fundamentals (2nd edition), CRC Press, Taylor and Francis Group, New York, 2011.

[19] U.S. Environmental Protection Agency (EPA), "Automobile emissions: An overview," EPA 400-F-92-007, Fact Sheet OMS-5, August 1994.

[20] D. Doniger, D. Friedman, R. Hwang, D. Losof and J. Mark, "Dangerous Addiction: Ending America's Oil Dependence," National Resources Defense Council and Union of Concerned Scientists, 2002.

[21] S. K. Jha and R. JHA, "Investigating The Indispensability of Renewable Energy Sources from the Standpoint of Conservation of Ecology and Environment," Invertis Journal of 
Renewable Energy, vol. 2, no. 4, pp. 219-233, Oct. 2012.

[22] L.A. Zadeh, "The concept of a linguistic variable and its application to approximate reasoning," Information Sciences 8, pp. 43-80, 1975.

[23] L. A. Zadeh, "Making computer think like people," IEEE Spectrum, 21, pp. 26-32, 1984.

[24] Pushpkant and S. K. Jha, "Performance Analysis of Conventional, Modern and Intelligent Control Techniques for Controlling CNC Machine Tool," International Journal of Applied Engineering Research, vol. 8, no. 6, pp. 51-55, March 2013.

[25] A. K. Yadav, P. Gaur, S. K. Jha, J. R. P. Gupta, and A. P. Mittal, "Optimal Speed Control of Hybrid Electric vehicle," Journal of Power Electronics, vol. 11, no. 4, pp. 393-400, July 2011.
[26] N. Tan and D. P. Atherton, "Stability and performance analysis in an uncertain world," Computing and Control Engineering Journal, pp. 91-101, April 2000.

[27] S. K. Jha, A. K. Yadav, Prerna Gaur, H. Parthsarathy, and J.R.P. Gupta, "Robust and Optimal Control Analysis of Sun Seeker System," Journal of Control Engineering and Applied Informatics, Vol.16, No.1, pp. 70-79, 2014. (Impact Factor: 0.228)

[28] William S. Levine, "Control System Applications," CRC Press, New York, 2000. 